
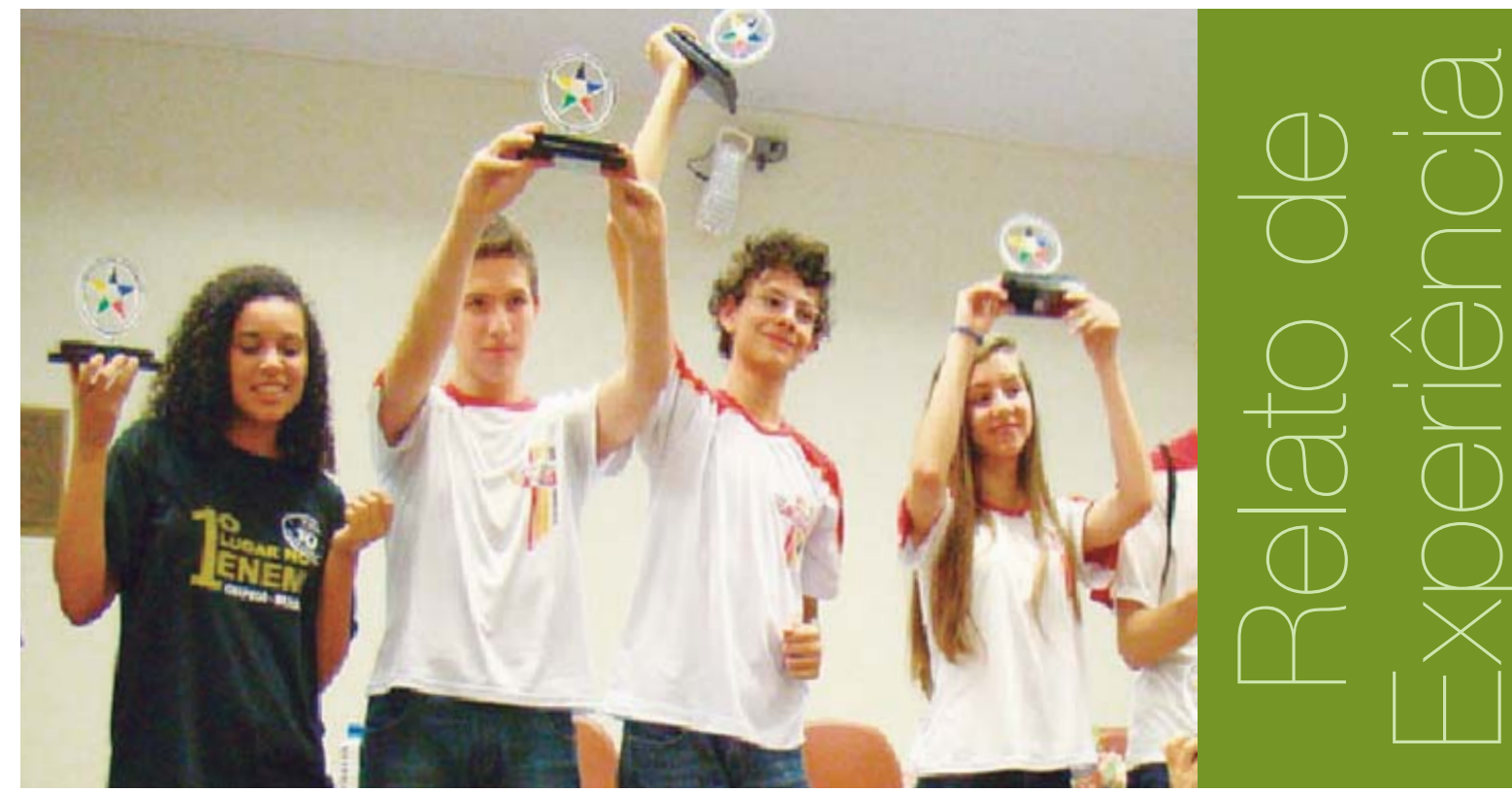

\title{
Olimpíada de Matemática: uma alternativa para estimular o estudo da matemática
}

\author{
Rosangela Ramon¹ - ro.ramon@unochapeco.edu.br \\ Andréia Beatriz Schmid² - andreia.s@unochapeco.edu.br \\ Michele Giovana Giachini - michelegiovana@unochapeco.edu.br
}

\section{RESUMO}

Este relato apresenta, de forma resumida, as atividades realizadas pela Olimpíada Regional de Matemática (ORM) da Unochapecó. A ORM é um projeto de extensão que envolve estudantes matriculados no ensino fundamental (anos finais) e médio de escolas da região. 0 projeto tem como objetivo estimular e incentivar o estudo da Matemática, desenvolver o raciocínio lógico, despertando assim o interesse e a imaginação dos alunos, mostrando uma disciplina diferente daquela resumida em regras e fórmulas.

\section{PALAVRAS-CHAVE}

Olimpíada. Resolução de problemas. Raciocínio lógico.

\section{ABSTRACT}

This report presents, in brief, the activities performed by the Olimpíada Regional de Matemática (Regional Mathematical Olympiad-RMO) at Unochapecó. The ROM is an extension project that involves students enrolled in elementary school (final years) and high schools students in the region. The project aims to stimulate and encourage the study of Mathematics, develop logical reasoning, thus, raising the interest and imagination of the students by showing a school subject different from the one summed up in rules and formulas.

\section{KEYWORDS}

Olympiad. Problem solving. Logical reasoning.

\footnotetext{
1 Mestre em Modelagem Matemática. Docente na Universidade Comunitária da Região de Chapecó - Unochapecó.

2 Mestre em Modelagem Matemática. Docente na Universidade Comunitária da Região de Chapecó - Unochapecó.

3 Acadêmica do curso de Licenciatura em Matemática na Unochapecó. Bolsista do projeto ORM.
} 


\title{
1 Relato de experiência
}

A Unochapecó realiza, desde 2004, a Olimpíada Regional de Matemática, por meio de extensão universitária. A Olimpíada busca estimular o estudo da Matemática nas escolas de ensino fundamental e médio do Oeste de Santa Catarina, Noroeste do Rio Grande do Sul e Sudoeste do Paraná, de forma a incentivar o pensamento crítico e investigativo, desenvolver o raciocínio lógico e a criatividade por meio da resolução de problemas.

\begin{abstract}
[...] aprender Matemática é mais do que manejar fórmulas, saber fazer contas ou marcar $\mathrm{x}$ nas respostas: é interpretar, criar significados, construir seus próprios instrumentos para resolver problemas, estar preparado para perceber estes mesmos problemas, desenvolver o raciocínio lógico, a capacidade de conceber, projetar e transcender 0 imediatamente sensível (PARANÁ, 1990, p. 66).
\end{abstract}

Segundo Dante (2005), a resolução de problemas deve levar o aluno a pensar, a desenvolver 0 raciocínio lógico, enfrentar situações novas e conhecer as primeiras aplicações da matemática. Com esse intuito, a ORM procura apresentar problemas desafiantes aos estudantes.

A Olimpíada Regional é realizada em duas fases e para três níveis, de acordo com a escolaridade dos estudantes. Nível I - para alunos matriculados no $7^{\circ}$ ou $8^{\circ}$ ano do ensino fundamental, nível II - para alunos matriculados no $8^{\circ}$ ou $9^{\circ}$ ano do ensino fundamental e nível III - para alunos matriculados em qualquer série do ensino médio.

Figura 1: Alunos realizando a prova de segunda fase da ORM na Unochapecó.

Fonte: Arquivos da ORM

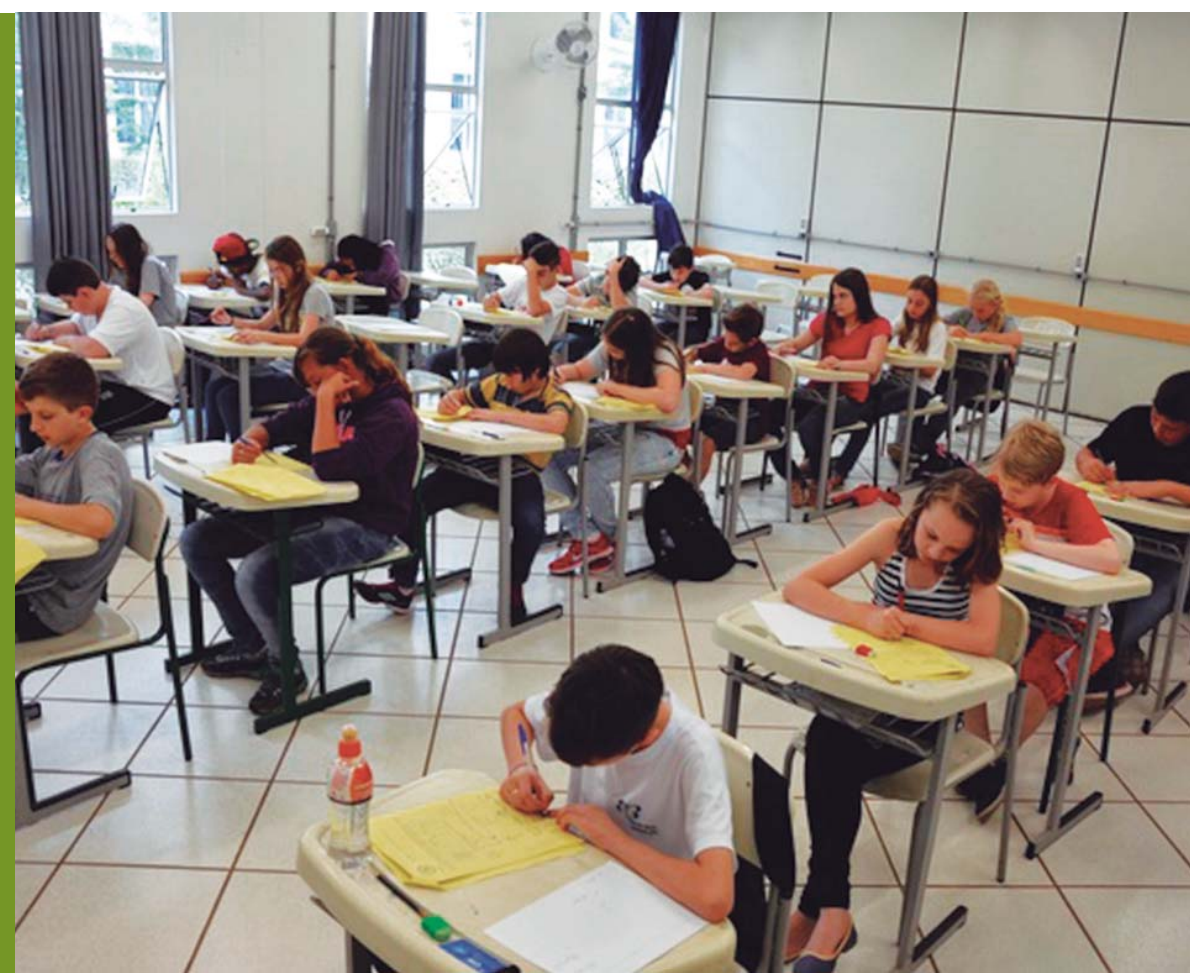

A primeira fase ocorre nas escolas, com aplicação de provas contendo de 20 a 25 questões de múltipla escolha. Esta primeira prova é a mesma aplicada na Olimpíada Brasileira de Matemática. Após correção das provas é estipulada uma nota de corte, visando atingir um total de 450 alunos que serão classificados para a próxima fase.

A segunda fase é realizada na Unochapecó (Fig.1) e contempla seis questões dissertativas elaboradas pelos professores do curso de licenciatura em Matemática.

No ano de 2014, contamos com a participação, na primeira fase, de 38 escolas, envolvendo 2.173 estudantes. Para a segunda fase foram classificados 424 estudantes, sendo 149 estudantes do nível I, 124 do nível II e 151 do nível III, distribuídos entre 26 escolas participantes.

Os alunos que apresentam melhor desempenho na última fase são convidados a participar do cerimonial de premiação (Fig.2), juntamente com familiares e a comunidade escolar. 


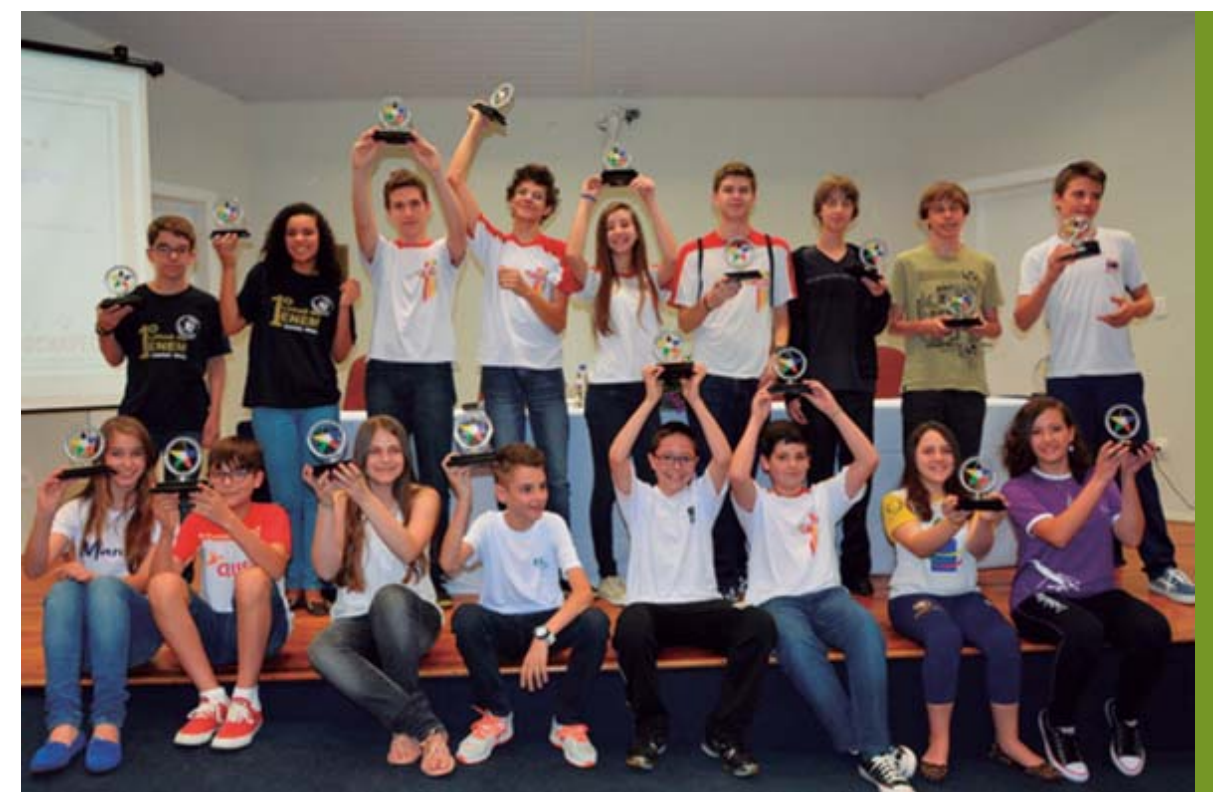

Figura 2: Alunos premiados na ORM em 2014.

Fonte: Arquivos da ORM

Além da realização das provas, a equipe da ORM realiza visitas nas escolas, mantém contato frequente por e-mail, fornece listas de problemas desafiantes, bem como, possibilita o deslocamento dos bolsistas do projeto até as unidades escolares para explorar e resolver estes problemas.

A cada ano que passa os alunos participantes da ORM surpreendem no que diz respeito à criatividade na resolução dos problemas propostos. A seguir são apresentados dois problemas da segunda fase da olimpíada, juntamente com a resolução realizada por dois estudantes.

\section{Problema - Nível I}

Em uma estrela mágica, a soma dos números de cada uma das linhas é a mesma. Resolva cada uma das expressões e depois complete a estrela mágica com os números que estão faltando. Você só deve usar números naturais de 1 a 12, de forma que não apareça o mesmo número mais de uma vez na estrela mágica.

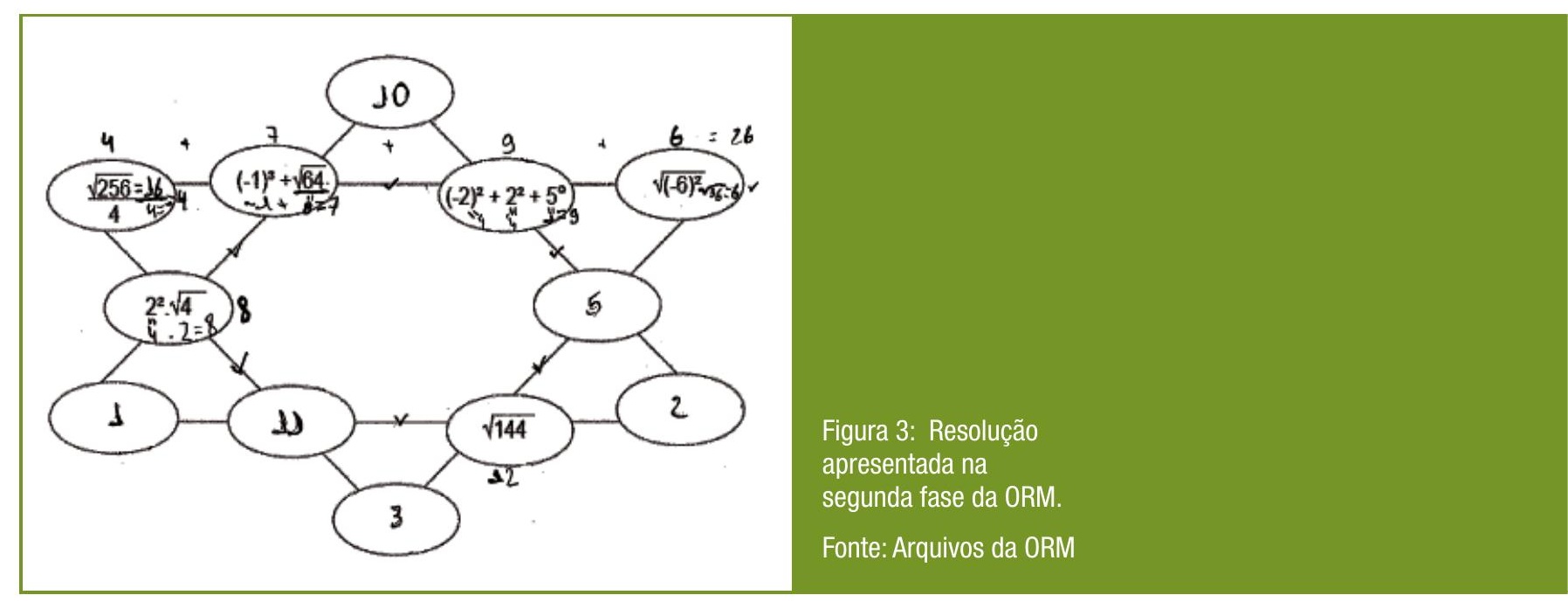

A Fig. 3 apresenta a resolução do problema por um aluno do sétimo ano de uma escola pública. No problema proposto, os conceitos de potenciação e radiciação estão presentes. Esses conceitos não são o ponto forte do problema, visto que são contemplados nas séries em que estudam. 0 que chama atenção é o fato que, na grande maioria das provas, apesar de terem conseguido resolver a parte referente aos conceitos matemáticos, os estudantes não conseguiram completar a estrela mágica. 0 raciocínio lógico, a criatividade e a interpretação são de extrema importância para a resolução deste problema. 


\section{Problema - Nível II}

Em uma partida de futsal, a distância entre a marca do pênalti (P) e o centro da linha do gol (M) é de 6 metros. A largura do gol é de 3 metros. Ao bater um pênalti, Davi deu um chute rasteiro tal que a bola deslizou por uma trajetória retilínea e formou um ângulo de $30^{\circ} \mathrm{com}$ a reta PM. Se 0 goleiro não tocou na bola e se o chute de Davi foi sem efeito, pode-se dizer que foi gol? Justifique.

Figura 4: Resolução apresentada na segunda fase da ORM.

Fonte: Arquivos da ORM

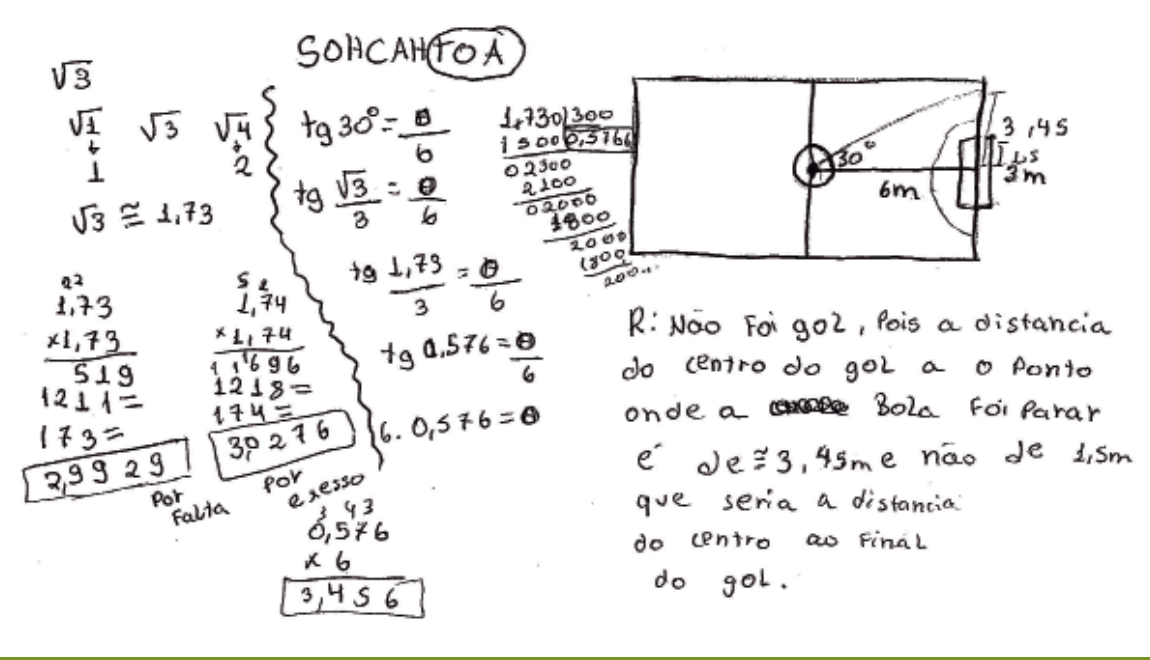

A Fig. 4 apresenta a resolução do problema por um aluno do nono ano de uma escola pública. Percebe-se que o estudante utilizou uma representação visual para compreensão do problema. Além de interpretar, usar o raciocínio lógico e a criatividade, dividiu o problema em várias etapas. É visível que o mesmo apresenta domínio dos conceitos de trigonometria, aproximação de raízes e operações com números reais.

As questões contempladas nas provas da Olimpíada fazem com que os estudantes exercitem a criatividade, raciocínio lógico e a busca de estratégias para resolução dos problemas.

A Olimpíada é uma forma de valorizar e incentivar os alunos ao estudo da matemática. É um estímulo, para que os estudantes aprofundem seus conhecimentos em matemática, não apenas pelo prêmio, mas pela autoestima em se destacar. No que diz respeito aos professores das escolas participantes, a olimpíada é um instrumento de renovação de ideias, de formas diversificadas de como os conceitos matemáticos podem ser explorados através de situações problemas. Para os bolsistas e voluntários do projeto, normalmente alunos do curso de matemática, é uma oportunidade de contato efetivo com o futuro campo de trabalho.

Mediante o exposto a ORM, enquanto projeto de extensão, possibilita transformar o conhecimento acadêmico em um bem público, potencializando e promovendo a difusão do saber científico.

\section{Referências}

Dante, Luiz Roberto. Matemática, volume único: manual do professor, 1. Ed. São Paulo: Ática, 2005.

PARANÁ. Secretaria de Estado da Educação. Departamento de Ensino de Primeiro Grau.

Currículo Básico para a Escola Pública do Paraná. Curitiba: SEED/DEPG, 1990. 